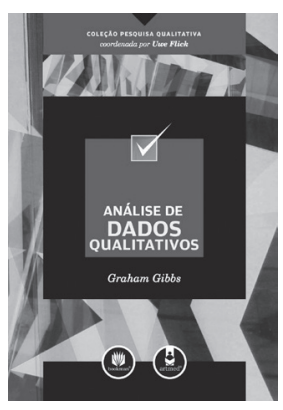

\title{
Gibbs G. Análise de dados qualitativos
}

\author{
Camila Amaral Moreno Freitas ${ }^{\mathbf{1}}$, Adriano Maia dos Santos ${ }^{\mathbf{1}}$ N Nília Maria de Brito Lima Prado1
}

DOI: 10.1590/0103-1104202012523

'ANÁLISE DE DADOS QUALITATIVOS'1 É UMA OBRA inclusa na 'Coleção Pesquisa Qualitativa', elaborada por Graham Gibbs, traduzida por Roberto Cataldo Costa e organizada em dez capítulos. O livro consiste em um aporte conceitual, teórico e metodológico imprescindível para subsidiar pesquisadores, professores universitários e estudantes de diversas áreas de graduação, desde as ciências sociais às ciências da saúde, em análises de todos os tipos de dados qualitativos.

No primeiro capítulo, o autor aborda a natureza da análise qualitativa e o processo analítico como elementos capazes de transformar os dados, a fim de que se tornem mais claros e compreensíveis. Para o autor, a pesquisa qualitativa lida com um grande volume de dados que possuem significados e simbolismos, portanto, a análise desvela não somente os temas que são discutidos pelos atores sociais, como também permite identificar as diversas formas de organização das comunicações e dos dados. Nesse processo, é importante verificar os tipos de dados e como serão analisados, bem como desenvolver técnicas adequadas.

Além dessas propostas mais gerais, Gibbs retrata a importância da consciência do pesquisador frente às informações que serão extraídas dos dados, a partir de diversas abordagens metodológicas, desde a descrição rica do material coletado até a aplicação de realismo e construtivismo. Tal abordagem propicia compreender o método, para além da técnica, a sua relação com a filosofia, a epistemologia e a metodologia, compreendendo as teorias de base, e a aplicação e, mesmo, a ressignificação do método (ou métodos) conforme as especificidades do objeto da pesquisa. Explicita, também, a adoção de concepções de caráter mais holístico, que têm como pressupostos teóricos o interpretivismo, a hermenêutica, o construtivismo etc. Por fim, o autor aborda nesse capítulo as questões éticas que estão imbricadas na pesquisa qualitativa, que devem ser priorizadas e tratadas antes do início da coleta de dados.

O segundo capítulo trata da preparação dos dados. Inicialmente, o autor aponta para a necessidade de realizar a transcrição dos dados produzidos a partir de entrevistas, observações ou notas de campo. Para tanto, ressalta que o processo de transcrição demanda tempo e esforço, e deve ser feito manualmente (pelo próprio pesquisador ou por um transcritor) ou a partir de um software que faz reconhecimento de caracteres derivados de entrevistas exploratórias abertas, questões abertas de questionários, textos de jornais, revistas, blogs e sítios da internet, a partir de arquivos de áudio, transcrição de imagens, dados obtidos de redes virtuais, correios eletrônicos, que permitem sistematizar categorias para análise dos dados com maior confiabilidade quanto à preservação do sentido original, ao minimizar equívocos.

Os temas escolhidos estão na ordem do dia, tendo em vista que, na literatura científica,

1 Universidade Federal da Bahia (UFBA) - Vitória da Conquista (BA), Brasil. c.amaralmoreno@outlook. com tem-se muitas discussões a respeito da pesquisa qualitativa com o uso de softwares para apoiar o processo, mas ainda é incipiente o detalhamento dos processos metodológicos e das técnicas usadas, integradas às tecnologias com o devido embasamento teórico. 
No terceiro capítulo, Gibbs enfatiza a redação como etapa fundamental durante a coleta de dados, e não apenas ao final do trabalho. Iniciar esse processo precocemente, segundo o autor, facilita o desenvolvimento de ideias sobre o que os dados indicam, de que forma eles podem ser analisados e, ainda, quais significados eles carregam. Entre os tipos de redação utilizados na pesquisa qualitativa, o autor aponta quatro prioritários: os diários de pesquisa; as discussões com outros pesquisadores, que agregam informações pertinentes e outros pontos de vista, que contribuam para aprimorar o processo de análise; as notas de campo; e, por fim, os memorandos.

O quarto capítulo apresenta a Codificação e a Categorização temáticas. A codificação, ao indexar o texto, permite que o pesquisador analise os dados de forma estruturada. Para tanto, Gibbs aponta que é importante desenvolver códigos coerentes. Para se codificar, é imprescindível desenvolver um olhar singular e intenso, uma vez que os códigos apresentam uma leitura analítica e teórica acerca do texto examinado. Com os dados codificados, procede-se à categorização, para agrupar o texto que foi codificado e uma metodologia que se utiliza dos aspectos simbólicos e polissêmicos implícitos no discurso, que se podem desvendar, organizar, agrupar e interpretar, a partir das categorias que vão surgindo e sendo reorganizadas durante a análise.

O quinto capítulo apresenta a análise de biografias e narrativas. As narrativas carregam o sentido de determinados eventos na vida das pessoas, e, para o autor, as pessoas podem ser incentivadas a contar suas histórias, especialmente quando o assunto diz respeito a algum evento marcante da vida. As biografias, são produtos mais metódicos e oriundos de solicitações mais específicas, mas também trazem aspectos da vida. Gibbs traz que, ao analisar as narrativas e as biografias, é possível identificar eventos que se sucedem ou que estão atrelados, assim, estas podem ser categorizadas como romances, comédias, tragédias e sátiras.

Após a transcrição e a codificação de dados, estes podem ser organizados hierarquicamente, como mostra o sexto capítulo. Essa forma de organização permite não só manter o controle sobre os dados que são codificados, mas, também, realizar análises entre as próprias hierarquias criadas, minimizar a possibilidade de duplicação de código e auxiliar na percepção de formas de interpretar os dados. Para o autor, é importante voltar às transcrições durante o processo de hierarquização, a fim de assegurar que todos os dados estejam codificados e que se incorporem novos códigos. Após a hierarquização, segue-se à realização de análises comparativas. O uso de tabelas na pesquisa qualitativa facilita uma comparação sistemática do conjunto de dados. Nesse momento, o pesquisador começa a desenvolver explicações e gerar modelos explicativos, que trazem traços importantes do fenômeno.

O sétimo capítulo apresenta a qualidade analítica e ética na pesquisa. De acordo Gibbs, a qualidade dos resultados é marcante em pesquisas qualitativas. A reflexividade que está presente no pesquisador qualitativo faz com que este não seja apenas um observador objetivo investigando um fenômeno, mas que reflita na pesquisa o lugar que ocupa, o que não significa que a pesquisa qualitativa não seja dotada de qualidade. Assim, o autor aponta que as pesquisas qualitativas requerem investimentos metodológicos que assegurem a qualidade da análise de dados. Entre eles, citam-se técnicas de validação, como a triangulação de dados, validação dos entrevistados, comparações e verificação das transcrições e dos códigos. No que concerne à qualidade ética na pesquisa, reforça a necessidade de minimizar ou eliminar danos que possam ocorrer aos participantes.

O oitavo capítulo aborda o uso dos Softwares de Análise de Dados Qualitativos (SADQ), como uma forma eficiente, sistemática e coerente de se gerenciar os dados. É possível, com esse recurso, contar frequência, fazer buscas e analisar os dados ali dispostos, de forma eficiente, consistente e sistemática do gerenciamento de dados, para busca e recuperação da informação.

O banco de dados obtido a partir de um SADQ permite ao pesquisador mais possibilidades que um banco de dados comum, mais facilidade de acesso aos textos codificados, facilita a seleção de trechos específicos, entre outros benefícios. Entres os SADQs mais utilizados por alunos e 
pesquisados, Gibbs destaca três: Atlas.ti, MAXqda e o NVivo. A escolha do software deve ser baseada no propósito das análises que serão realizadas.

No nono capítulo, Gibbs discute o uso de softwares para busca de palavras e expressões como um aliado do pesquisador, uma vez que diminuem a possibilidade de ocorrência de vieses enquanto se codifica ou se faz leitura exaustiva e análises dos dados. A busca permite ao pesquisador conhecer os dados, identificar trechos semelhantes, verificar se todo o texto está codificado e ainda realizar busca temática. Ainda nesse capítulo, o autor descreve os atributos como dados variáveis relacionados ao contexto e ao indivíduo, que permitem ao pesquisador controlar acessos e buscas através de códigos. Em síntese, após a codificação e a organização em categorias e subcategorias, os processos de busca e recuperação da informação, de busca das citações e falas dos entrevistados, de inferência, de interpretação e de generalização das fontes ficam mais facilitados para a análise qualitativa.

Por fim, o décimo capítulo, intitulado 'Agrupando tudo', traz uma breve síntese do que foi apresentado e discutido nos capítulos anteriores. Consoante com os argumentos aqui tratados, o leitor poderá observar em cada capítulo e, sobretudo, nas conclusões de cada um deles, que o foco das indagações é integralmente atingido. Cada capítulo revela as peculiaridades relativas à pesquisa qualitativa, a riqueza da dinâmica e do confronto com a realidade complexa, o aprimoramento e a sistematização do pensamento e dos construtos teóricos e metodológicos necessários para a clarificação e aproximação do pesquisador com o objeto de estudo.

Iniciativas dessa natureza contribuem, sem dúvida, para o estímulo ao debate em torno das alternativas analíticas, teórica e metodologicamente fundamentadas, ampliando o desvelamento do entendimento subjetivo e intersubjetivo, ao tempo que gera reflexões acerca dos conhecimentos e de como estes podem contribuir para o avanço da ciência e da técnica e para um cuidado mais específico com os indivíduos, os grupos e as coletividades, o objeto primordial da pesquisa qualitativa.

\section{Colaboradores}

Freitas CAM (0000-0002-1841-2260)* contribuiu para a concepção, o desenho e elaborou o trabalho criticamente, para conteúdo intelectual importante; aprovou a versão final a ser publicada; e é responsável por prestar contas de todos os aspectos do trabalho, garantindo que as questões relacionadas à precisão ou integridade de qualquer parte sejam devidamente investigadas e resolvidas. Santos AM (0000-0001-9718-1562)* contribuiu para a concepção do trabalho, revisou criticamente o conteúdo intelectual importante e aprovou a versão final a ser publicada; e é responsável por prestar contas de todos os aspectos do trabalho, garantindo que as questões relacionadas à precisão ou integridade de qualquer parte sejam devidamente investigadas e resolvidas. Prado NMBL (0000-0001-8243-5662)* trabalhou para a concepção, no delineamento e na avaliação da versão final; e é responsável por prestar conta de todos os aspectos do trabalho, garantindo que as questões relacionadas à precisão ou integridade de qualquer parte sejam devidamente investigadas e resolvidas.
*Orcid (Open Researcher and Contributor ID).

\section{Referência}

1. Gibbs G. Análise de dados qualitativos. Porto Alegre, Artmed; 2009. 